\title{
Enhancement of operating efficiency of grinding equipment
}

\author{
Romanovich Alexey Alexeevich \\ Department of Lift-and-Carry and Road Machinery \\ Belgorod State Technological University named after \\ V.G. Shukhov \\ BSTU named after V.G. Shoukhov \\ 308012, Kostukov St, 46 \\ Belgorod, Russia \\ alexejrom@yandex.ru
}

\author{
Romanovich Marina Alexeevna \\ Department of Lift-and-Carry and Road Machinery \\ Belgorod State Technological University named after \\ V.G. Shukhov \\ BSTU named after V.G. Shoukhov \\ 308012, Kostukov St, 46 \\ Belgorod, Russia \\ alexejrom@yandex.ru
}

\begin{abstract}
The results of the experimental studies on the process of clinker grinding pre-crushed in a press roller mill and in a ball mill equipped with the energy exchangers are described in the article. The effect of clinker grinding pressure on the amount of deagglomeration forces of its compacted plates is determined depending on the direction of force exertion. The designs of energy-exchange devices are proposed, which make it possible to create an effective power action of grinding bodies on the grinding material. The effect of load factors of the grinding bodies of the first and second ball mill chambers, their lengths, inclination angles and mutual arrangement of energy exchange devices on the output parameters of the grinding process was studied and their rational values were obtained. Comparative tests of cement samples obtained in the energy-saving machines have made it possible to state that their beam strength for the compression and bending is $15-20 \%$ higher compared to the traditional way of grinding.
\end{abstract}

Keywords-press roller mill, ball mill, energy exchangers, specific energy consumption, pressure.

\section{INTRODUCTION}

In the production of binding materials, various building mixtures and products, among the most energy-intensive processes, there are the processes of crushing and grinding with the world energy consumption of about $10 \%$. At the same time, the power consumption significantly increases with the dispersion of the product obtained.

It is known [1] that power consumption for material crushing amounts to $10-21 \mathrm{~J} / \mathrm{g}$ and for fine and superfine grinding it equals to $360-3600 \mathrm{~J} / \mathrm{g}$.

Therefore, the studies aimed at the grinding technology improvement and equipment enhancement for the purpose of reduction of the energy requirement of the process are topical.

When producing the cement, the annual volume of which is increasing and currently exceeds 2.5 billion tons globally, 40 to $70 \%$ of the total electric power is consumed during the grinding of raw materials and cement materials that mainly takes place in the ball mills [2].
The issues related to the development of new grinding equipment and the effectiveness increase of the existing equipment were studied by the researchers and practitioners in Russia and abroad. They developed an energy-saving technology to obtain cement using grinding complex that consisted of two parts: a press roller shredder and a ball mill (PRS-BM) [3-4].

In the cement manufacturing process, the implementation of the step-by-step grinding method due to the use of a ball mill (BM) and a press roll machine, allows one to increase productivity and to reduce the specific energy consumption by 20-40\% [5-6]. However, after the pressure treatment between the rolls of PRS, the shape and the texture of material differ from the feedstock, and special conditions for its grinding in a ball mill are required.

Besides, application of several grinding modes in the ball mills may result in certain difficulties and reduce the efficiency of grinding.

\section{EXPERIMENTAL PART}

The analysis of the material crushed in PRS made it possible to state that it has the form of compressed plates and an anisotropic texture with the maximum strength in the direction of grinding force; the constituent particles have a microdefect structure (Fig. 1, 2) which requires special conditions for its deagglomeration and grinding. 




Fig. 1. Initial matreial (clinker)

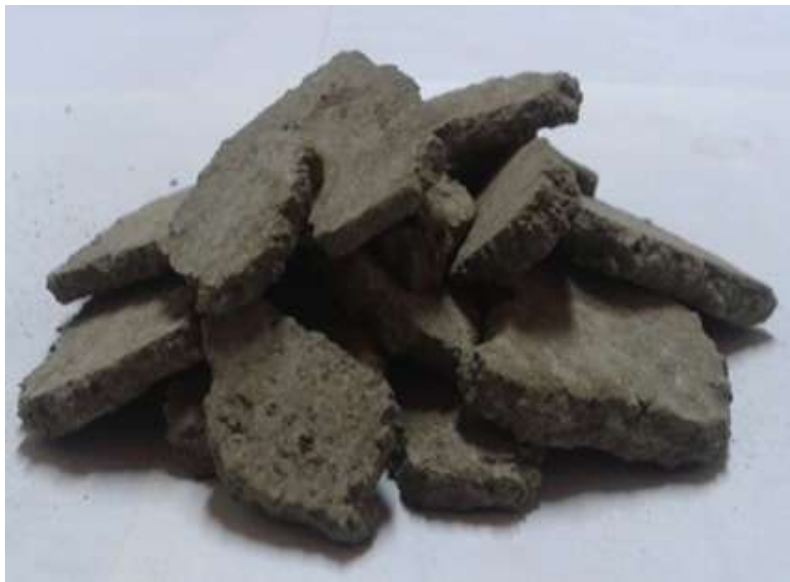

Fig. 2. Clinker's shape after grinding in PRS

In the course of the experimental studies devoted to the influence of grinding forces on the size of their pressed plates deagglomeration (Fig. 3) it was found out that during the pressing pressure increase it is not only the crushing degree of the material that increases, but also the strength of the compacted plates. That is why, depending on the direction, it is necessary to apply various efforts for their destruction. For example, when grinding clinker with the pressure equal to 240 $\mathrm{MPa}$, the forces needed for deagglomeration of the pressed plates when applying force in the direction of material pressing are equal to $P$ dir. disag. $=22 \mathrm{MPa}$, and in the perpendicular direction are equal to $P_{\text {trans. disag. }}=5 \mathrm{MPa}$, which is much lower. This indicates that to effectively destroy materials that are crushed and pressed in plates using PRS, it is advisable to make efforts in the direction perpendicular to the force action in PRS.

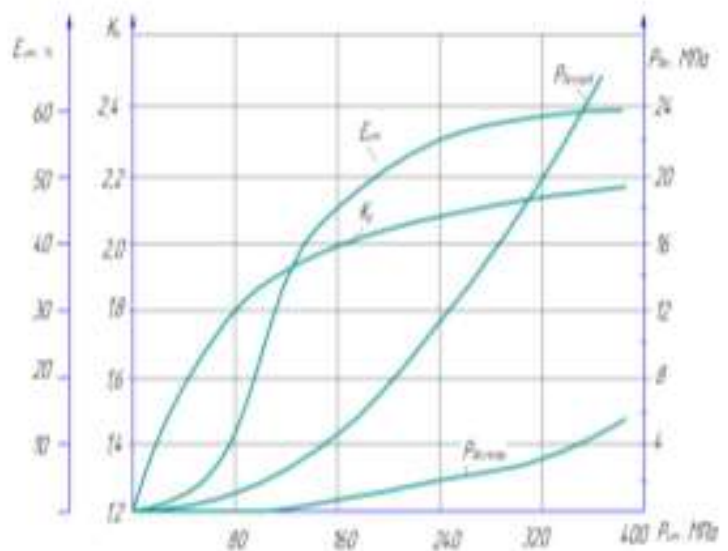

Fig. 3. Influence of clinker grinding pressure on the force value of deagglomeration

In view of the above mentioned studies we may say that when the pre-shredded materials are ground in a ball mill, they should be exposed to a short-time shock-shear action of the grinding bodies in the first deagglomeration chamber of the pressed plates and to a crushing-abrading action in the second chamber for the final grinding. Based on the analysis of literature sources [4] and earlier studies carried out using the model of a mill with the transparent casing, it was stated that such conditions for the material grinding make it possible to get the installation of a mill of the energy-exchange devices (ED) in a drum: a double-action blade (DAB) and an elliptical segment (ES) (Fig. 4).

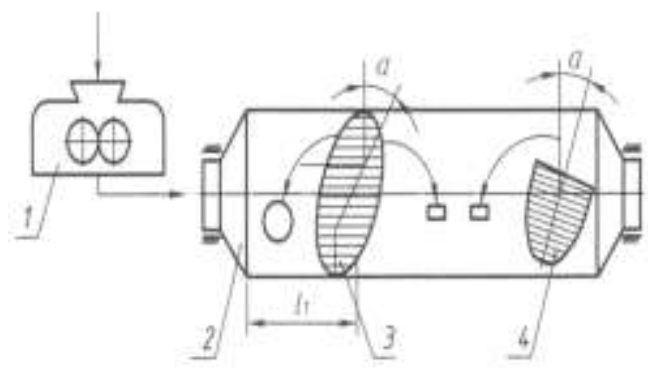

Fig. 4. Press roller mill and ball mill equipped with energy exchangers: 1 PRS; 2- mill drum; 3 -double-action blade; 4- elliptical segment

However, depending on the installation diagram of the energy exchangers in the drum, the dynamic action mode of the grinding bodies on the material to be ground varies greatly. Besides, the efficiency of the grinding process of the materials depends on the mill load factors, etc.

Therefore, in order to determine their rational values, the authors carried out experimental studies using the laboratory equipment (ball mill): $\mathrm{D} \times \mathrm{L}=0.5 \times 1.95$ meters equipped with the energy exchangers.

Applying the method of mathematical planning to carry out the experiment, the dependence of $Q, N, q=f\left(K_{1} ; K_{2} ; L_{1}\right.$; $\alpha ; \xi)$ was studied. The parameter studied were as follows: the loading factors of the grinding bodies of the first $K_{1}$ and the second $K_{2}$ mill chambers, the length of the first chamber $l_{1}$, the 
inclination angle of ES $\alpha$ and its displacement angle $\xi$ with respect to the double-action blade.

To assess the efficiency of deagglomeration process and clinker grinding in BM with energy exchangers, the following parameters were taken as output parameters: productivity Q reduced to a total residue on the $\Sigma R_{008}$ sieve of $10 \%$, power consumption of drive $\mathrm{N}$ and specific energy consumption $q$.

Basing on the results of the study, graphical dependencies were obtained (Figures 5-8).

Analysis of diagram $q=f\left(\xi ; K_{2}\right)$ (Fig. 5) made it possible to determine that the mutual bracing of the double-action blade and the elliptical segment in the mill drum has a significant influence on the grinding process. The best results of their joint work are achieved when the double-action blade and the elliptical segment are located in the mill drum with their working surfaces parallel to each other; in this regard $q=22.7$ $\mathrm{Wh} / \mathrm{kg}(\mathrm{K} 2, \mathrm{~K} 1, \alpha ; 11$ = const $)$.

This is confirmed by the fact that the position in the mill drum of the elliptical segment relative to the double-action blade at an angle of $180^{\circ}$ leads to the alternating action of the energy exchangers on the grinding load, which makes it more mobile and helps to enhance the abrasive action of grinding media on the material to be crushed. Such diagram of the energy exchanger installation contributes to the intensity of the grinding process of pre-crushed materials in the second chamber of the mill.

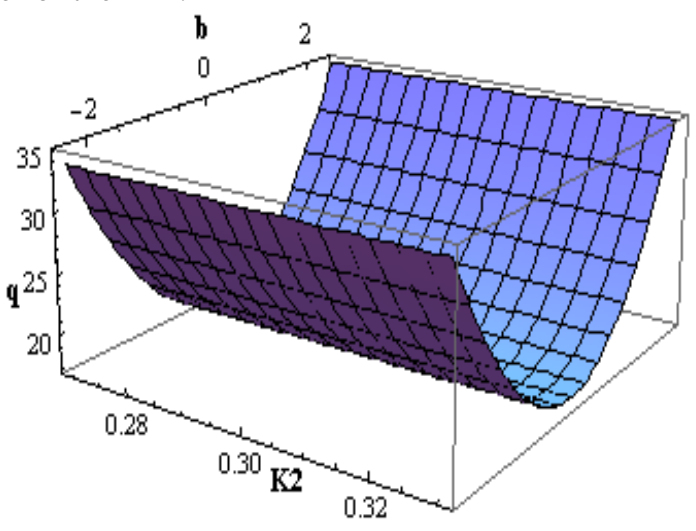

Fig. 5. Influence of the displacement angle of the double-action blade relative to the elliptical segment on the specific energy consumption $\left(K_{1}=\right.$ $\left.0.18 ; \alpha=-30^{\circ} ; l_{1}=0.65 \mathrm{~m}\right)$

With the help of the graphical dependence analysis $N, Q=f\left(K_{1}, l_{1}\right)$ (Fig. 6, 7), it was established that the length change of the first chamber in the range from $11=0.4 \mathrm{~m}$ to 11 $=0.9 \mathrm{~m}$ resulted in the extreme performance. Hence, the length of the first chamber when grinding the clinker, which was preliminarily ground in PRS is $11=0.6 \mathrm{~m}$, which corresponds to $l_{1}=0.3 L$, where $L$ is the length of the mill's drum. With an increase in the load factor of the grinding bodies of the first mill chamber in the range from $K_{l}=0.15$ to $K_{1}=0.18$, power consumption increases proportionally from $\mathrm{N}=4.15 \cdot 103 \mathrm{~W}$ to $\mathrm{N}=4.55 \cdot 103 \mathrm{~W}$, i.e. by $8.5 \%$. The capacity increases proportionally to the mass increase of grinding bodies in the first chamber from $Q=164.1 \mathrm{~kg} / \mathrm{h}$ to $Q$
$=165.7 \mathrm{~kg} / \mathrm{h}$, i.e. by $2-3 \%$. However, when $K_{1}$ is increased up to 0.18 , a capacity reduction is observed which entails growth of the specific energy consumption from $q=22.7$ to $q=23.5$ $\mathrm{Wh} / \mathrm{kg}$. Basing on the studies described above, it is possible to come to the following conclusion: the grinding process is effective at $K_{1}=0.16-0.18$, which is much lower compared to the clinker grinding in a traditional way in a ball mill equal to $K_{1}=0.3$.

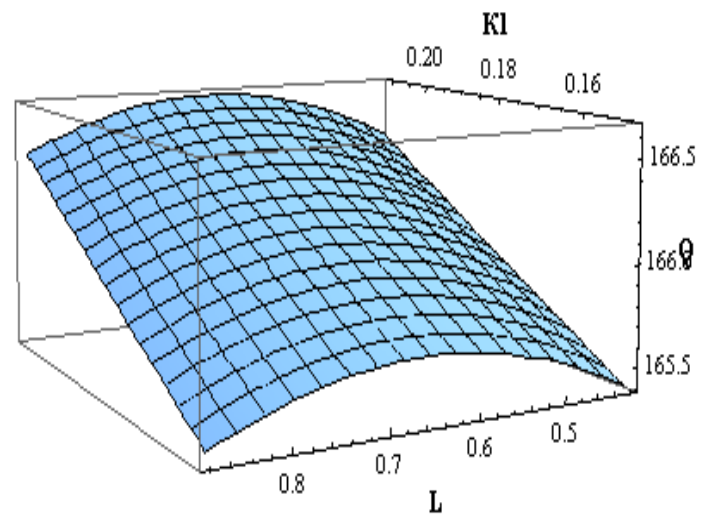

Fig. 6. Influence of the first chamber length and the load factor of grinding bodies of the first chamber on productivity $\left(K_{1}=0.18 ; \xi=0^{\circ} ; K_{2}=0.3\right)$.

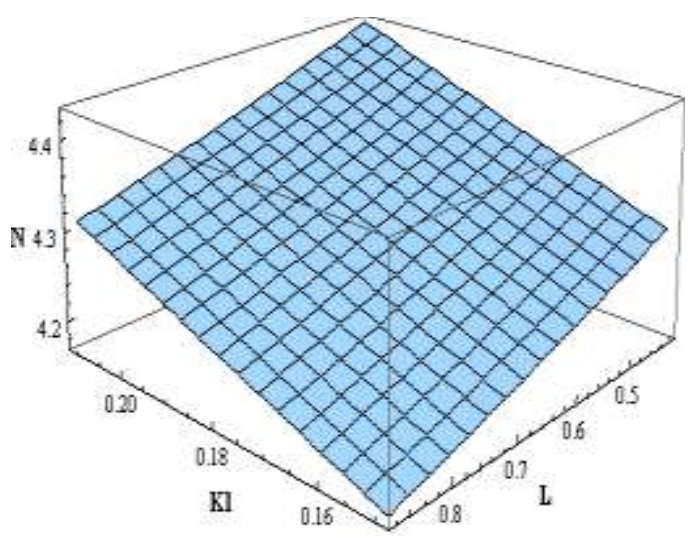

Fig. 7. Influence of the first chamber length and the load factor of grinding bodies on productivity $\left(\xi=0^{\circ} ; K_{2}=0.3\right.$ )

Graphical dependence analysis (Fig. 8) showed that when the inclination angle of the elliptical segment changes from the vertical axis of the mill $\left(\alpha=0^{\circ}\right)$ towards the discharge bottom by an angle of $\alpha=-30^{\circ}$ ( 0.53 radians), a specific energy consumption decreases to the extremum: $q=23.0$ $\mathrm{Wh} / \mathrm{kg}$. A further inclination angle increase of the elliptical segment of about $\alpha=-48.2^{\circ}$ leads to an increase in the specific energy consumption from $q=23.0 \mathrm{Wh} / \mathrm{kg}$ to $q=23.7$ $\mathrm{Wh} / \mathrm{kg}$ (by 3\%). The change of the inclination angle of the elliptical segment from the vertical axis of the mill $\left(\alpha=0^{\circ}\right)$ from the discharge bottom leads to a sharp increase in the specific energy consumption. This is due to the fact that when the elliptical segment is tilted towards the discharged bottom of the mill a mixed operation mode of grinding bodies is performed in the second mill chamber since some grinding bodies are partially captured by the segment and raised up, thereby creating a waterfall grinding mode instead of the 
required cascade one. Basing on the studies and analysis mentioned above, it is possible to say that the most rational inclination angle of the elliptical segment during the grinding process of the preliminarily ground materials in PRS should be the angle of $30^{\circ}$ ( 0.53 radians), and it should be tilted toward the discharge bottom of the mill. It can also be explained by the fact that the position of elliptical segment contributes to the intense crushing and abrasive actions of the grinding load on the material to be crushed without disturbing the cascade mode.

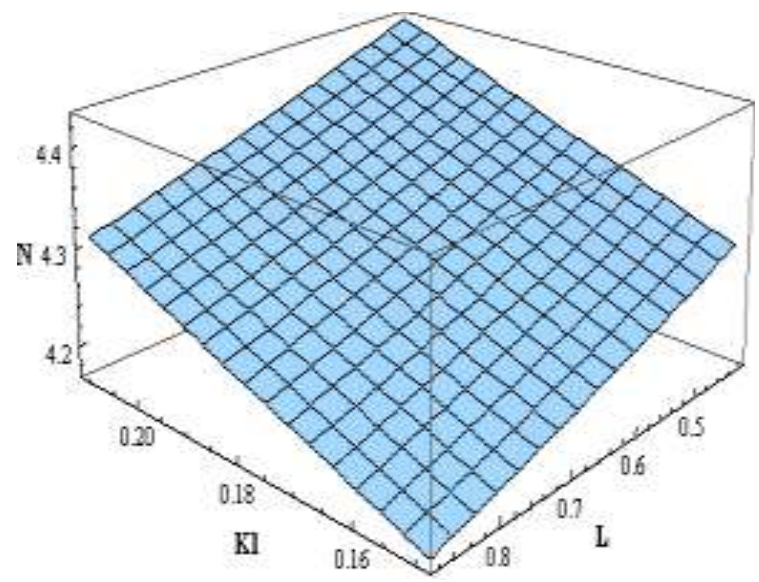

Fig. 8 Influence of the elliptical segment inclination angle on the value of specific energy consumption in different load modes of grinding bodies of the second chamber: $\left(K_{1}=0.16 ; \xi=0^{\circ} ; l_{l}=0.6 \mathrm{~m}\right)$

Thus, in the course of studies it was established that the nature of the dynamic influence of grinding bodies in the ball mill is significantly influenced by the mutual arrangement of energy exchangers in the longitudinal and in cross sections of the mill body.

As a result of graphical dependency analyses (5-8), it was found that the process of grinding of the materials that were preliminarily ground in PRS demonstrates high performance with the following load factors of mill chambers: $K_{l}=0.18, K_{2}$ $=0.3$, the length of the first chamber $L_{l}$ is equal to 0.65 meters, which comprised $1 / 3$ of total length of the drum with the specific energy consumption amounting to $\mathrm{W}, q=22.9 \mathrm{Wh} / \mathrm{kg}$.

In order to confirm the results of studies and set out the advantages of using energy exchangers, comparative industrial tests were carried out, using the mills with the size of $\varnothing 3.2 \times 15 \mathrm{~m}$ equipped with the axillary power system, and without them.

Energy exchangers were made in the form of double-acting blades (DAB) installed along the movement of the crushed material (Fig. 10) and an elliptical segment (ES) installed in the discharge grid of the mill (Fig. 11). As a result of the use of energy exchangers, the capacity of mills with the size of $\varnothing 3,2 \times 15 \mathrm{~m}$ equipped with the elliptical segment has increased by $20 \%$; the specific energy consumption has decreased by $15 \%$.

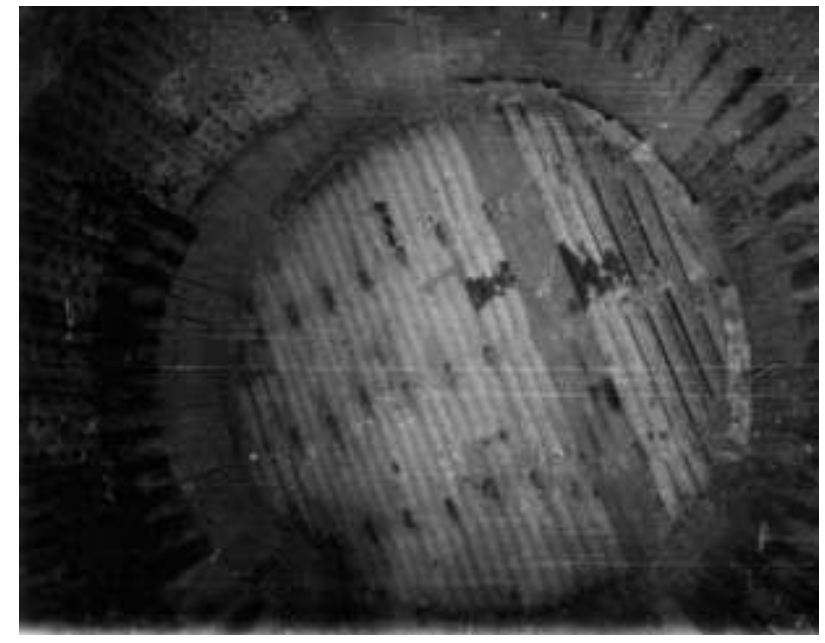

Fig. 9 Double-acting blade installed in the ball mill $\varnothing 3.2 \times 15 \mathrm{~m}$

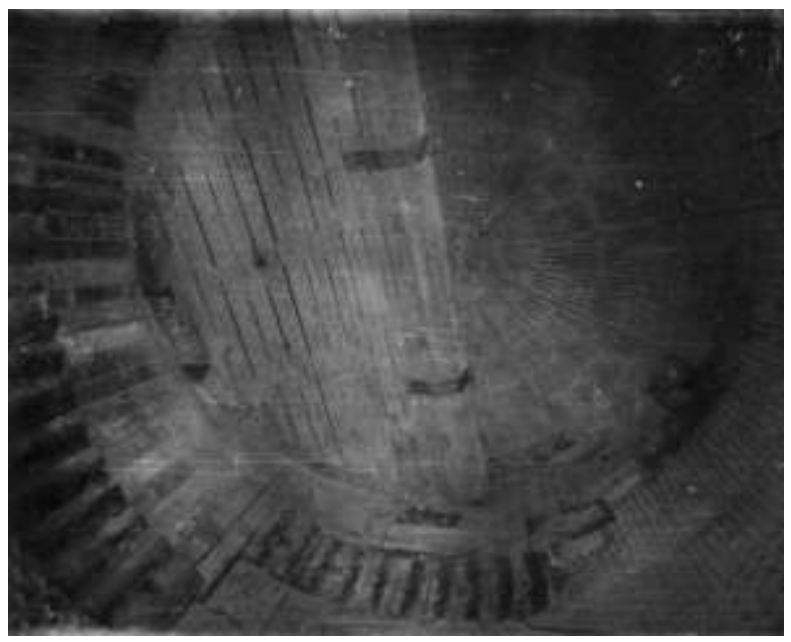

Fig. 10 Blade elliptical segment installed at the discharge bottom of the mill $\varnothing 3.2 \times 15 \mathrm{~m}$

Comparative tests of cement samples obtained in the energy-saving machines and ball mill have made it possible to state that their beam strength for the compression and bending is $15-20 \%$ higher compared to the traditional way of grinding. The reason for this is that the structure of samples activated from the cement which was obtained using energy-saving machines (Fig. 9, a) has more dense homogeneous structure with good adhesion of cement stone to the filling material compared to the structure of samples from the reference cement (Fig. 9, b).

In the heterogeneous structure of the sample obtained from traditional cement, (Fig. 9 (b)) large pores covered with big crystals of calcium hydrosilicate of various bases are clearly seen when they are magnified 18 thousand times.

The study of the sample (Fig. 9, a) proves the existence of more dense and homogeneous structure of the cement stone. The defects of the structure are covered with the dense net of calcium hydrosilicates. The research data of the microstructure of cement stone clearly explain improved strength 
characteristics of a cement sample which was obtained using energy-saving machines. This is caused by different physics of destruction of the initial material used in the energy-saving machines (PRS + BM with ES), which at the initial stage is distorted between the rolls of press roller shredder under high pressure resulting in a more developed and activated particle structure.
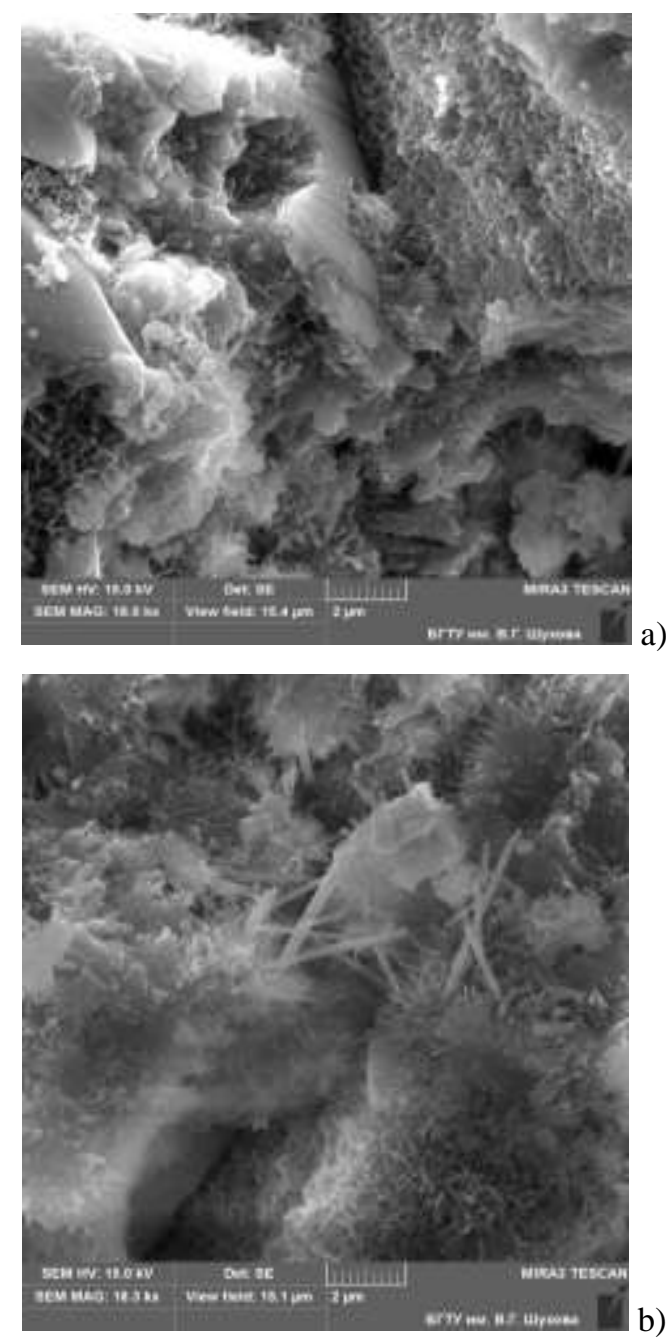

Fig. 11 Structure of cement stone samples: $a$ - in the energy-saving machines; $b$ - in the ball mill.

Thus, the comparative tests of cement samples obtained in the energy-saving machines (PRS + BM with EE) have made it possible to state that their beam strength for the compression and bending is $15-20 \%$ higher compared to the traditional way of grinding, revealing that they have more dense homogeneous structure with good adhesion of cement stone to the filling material compared to the structure of the samples obtained from the reference cement.

\section{SUMMARY}

As a result of the carried out analysis of the material crushed in PRS, it was found out that the material has a shape of compressed plates with maximum strength in the direction of grinding force application and the constituent particles have a microdefect structure which requires special conditions for its deagglomeration and grinding. Depending on the direction, their destruction requires application of different efforts.

Application of energy exchangers and their mutual arrangement in the longitudinal and cross sections of the mill drum has a significant effect on the nature of the dynamic action of grinding bodies.

As a result of the conducted studies and analysis of the obtained graphical dependencies (5-8), it was found that for the purpose of energy saving they should be exposed to a shorttime shock-shear action of the grinding bodies in the first mill chamber and to a crushing-abrading action in the second chamber, which is ensured by the installation of energy exchangers in the BM of the drum. The rational operation of the ball mill is obtained when the elliptical segment is tilted from the discharge bottom at an angle of $30^{\circ}$ from the vertical axis of the mill drum parallel to the double-action blade. The load factors of its chambers amounts to $K_{1}=0.18, K_{2}=0.3$, length of the first chamber $L$ is equal to 0.65 meters, which comprised $1 / 3$ of total length of the drum.

Comparative tests of cement samples obtained in the energy-saving machines (PRS $+\mathrm{BM}+\mathrm{EE}$ ) have made it possible to state that their beam strength for the compression and bending is $15-20 \%$ higher compared to the traditional way. This is caused by different physics of destruction of the initial material used in the energy-saving machines (PRS + BM with EE)

\section{Acknowledgment}

The work has been carried out in the framework of the Strategic Development Program on the basis of Belgorod State Technological University named after V.G. Shukhov (BSTU) using the equipment of the High Technology Center at BSTU.

\section{References}

[1] A.A. Romanovich, "Energy saving in the manufacture of building products," Bulletin of BSTU named after V.G. Shukhov, vol.3, pp. 6971, 2011.

[2] J. Binner, R. Assumus, E.V. Schegolyaev, "The technology of grinding and classification of slag", Cement and its application, 5, pp. 31-36, 2006

[3] Z. Strasser, "Current state of grinding technology from KHD Humboldt Wedag AG," Cement and its application, 1, pp. 27-30, 2002.

[4] L.G. Romanovich, M.A. Romanovich, V.V. Vybornova and V.N Riapukhina, "Small business is a sphere of innovation in the age of globalization," Journal of Applied Engineering Science, 12 (4), pp. 297 301,2014

[5] "The world's largest roller mills," International cement review 1, pp 43-44, 2000.

[6] V.S. Bogdanov, I.A. Semikopenko, P.P. Penzev and A.N. Maslovskaya, "Desintegrator with unit high-speed flow of crushed material," Bulletin of BSTU named after V.G. Shukhov, 1, pp. 101-103, 2009.

[7] V.Z. Pirotsky, Cement Mills: operation optimization, St. Petersburg: Publishing House of the Center for Informatization of Education, 1999 p.145.

[8] M.A. Romanovich, A.A. Rudychev, L.G. "Romanovich. Venture capital investigation of innovative companies abroad and in Russia," Bulletin of BSTU named after V.G. Shukhov, 4, pp. 124-127, 2011. 
[9] V.K. Pobeda, "Press roller grinders JSC "Tyazhmash," Cement and its application, 4, pp. 26-28, 2007.

[10] M. Metsman, Y. Krump, "Technology to upgrade the cement plants of the company KHD Humboldt Wedag GmbH," Cement and its application, 3, pp. 40-4, 20053.

[11] H. Wustner, "Energy-saving with the roller press comminution process," World Cement, 3, pp.94-96, 1986.

[12] N. Patzelt, "Current level of development and application of compressor roll of crushers," Cemento hormigon, 635, pp. 977-991, 1986. [Electronic edition: http: //www.xsk.euro.ru/index.html].
[13] A.A. Romanovich, "Performance review and principal directions for development of grinding equipment in cement factory," Journal of Engineering and Applied Sciences, 9(11), pp. 2367-2370, 2014.

[14] V.V. Sevostyanov, I.I. Targonski, A.A.Romanovich, and A.A. Goncharo, "Energy saving milling aggregates with internal recycling of the milled materials," Glass and Ceramics, 50 (4), pp. 180-184, 1993. 